\title{
A multidrug resistance transporter/serine protease gene is required for prestalk specialization in Dictyostelium
}

\author{
Gad Shaulsky, Adam Kuspa, ${ }^{1}$ and William F. Loomis ${ }^{2}$ \\ Center for Molecular Genetics, Department of Biology, University of California, San Diego, La Jolla, California 92093 USA
}

\begin{abstract}
The prestalk-specific gene, $\operatorname{tag} B$, was disrupted by restriction enzyme-mediated integration (REMI) mutagenesis. Mutant aggregates exhibit a cell-autonomous defect in specialization of PST-A cells, a prestalk subpopulation that forms the tip and eventually forms the stalk of the fruiting body. Cooperative (non-cell-autonomous) defects were found in sporulation and in specialization of prestalk cells that eventually form the upper cup of the fruiting body (PST-O). The pattern of ecmA::lacZ expression in mutant tagB ${ }^{-}$cells defines a primary prestalk population, PST-I, from which other prestalk cells differentiate. After PST-A cells differentiate, they induce remaining PST-I cells to become PST-O cells. Subsequently, prestalk cells induce encapsulation of prespore cells during culmination. $\operatorname{tag} B$ is homologous to serine protease and to multidrug resistance (MDR) transporter genes, implying a mechanism of action that includes proteolysis and export of peptide signals. Intercellular communication via TagB may mediate integration of cellular differentiation with morphogenesis.
\end{abstract}

[Key Words: Dictyostelium; differentiation; MDR transporter genes; serine proteases; prestalk specialization]

Received February 2, 1995; revised version accepted March 16, 1995.

The initial events in cell-type divergence in Dictyostelium discoideum are spatially independent and can be recognized as early as $8 \mathrm{hr}$ after the onset of development (for review, see Loomis 1993). Prespore cells that are marked with the Escherichia coli $\beta$-galactosidase (lacZ) fused to a $\cot B$ regulatory element $(\cot B: \because \operatorname{lac} Z)$ are initially dispersed throughout the loose aggregate at $8 \mathrm{hr}$, but $4 \mathrm{hr}$ later they sort out to the lower part of the mound. Prestalk cells that are labeled with ecm $A:: l a c Z$ also differentiate in a spatially random manner shortly after the initiation of prespore development. At the tight aggregate stage, $12 \mathrm{hr}$ after the initiation of development, the proportions of the two cell types are well defined as $70 \%$ prespore cells and $30 \%$ prestalk cells. Spatial sorting is also complete at this stage and morphogenesis starts to take place as prestalk cells sort to the top of the aggregate and form a tip. The tip extends to form a fingerlike structure that can fall over and migrate on the substratum (for review, see Loomis 1993). The anterior $20 \%$ of the migrating slug consists of prestalk cells that can be divided into two subpopulations on the basis of the pattern of expression of lac $Z$ gene fusions with subdomains of the ecm $A$ regulatory element. The most anterior portion of the slug is occupied by PST-A cells that will eventually give rise to the cellular stalk. The rest of the

\footnotetext{
${ }^{1}$ Present address: Department of Biochemistry, Baylor College of Medicine, One Baylor Plaza, Houston, Texas 77030 USA.

${ }^{2}$ Corresponding author.
}

prestalk region consists of PST-O cells that will eventually give rise to the upper cup of the sorus and may participate in formation of the cellular stalk. The posterior $80 \%$ contains mainly prespore cells. The few prestalk cells found in the posterior region are called anterior-like cells and they ultimately participate in formation of the lower cup and the basal disk of the fruiting body (Jermyn et al. 1989; Williams et al. 1989).

Cell-type proportioning in Dictyostelium is size invariant and is dynamically maintained through intercellular communication (Loomis 1993). Slugs ranging in size from $10^{3}$ to $10^{5}$ cells consist of $70 \%$ prespore and $30 \%$ prestalk cells, but when prespore cells are surgically removed from a slug (Raper 1940), or when they are poisoned by expression of $\cot B:$ ricinA (Shaulsky and Loomis 1993), prestalk cells regulate to regenerate the proper proportion of prespore cells. A limited number of prespore cells have been shown to regulate and take on a prestalk cell fate following prolonged slug migration (Sternfeld and David 1982; Harwood et al. 1991; H. MacWilliams, pers. comm.), but poisoning prestalk cells with an $e c m A$ ::ricin $A$ gene fusion does not result in conversion of prespore cells to replace the dying prestalk cells (Shaulsky and Loomis 1993). Strains carrying ecmA::ricinA, however, suffered from a $50 \%$ reduction in sporulation efficiency, indicating that prestalk cells have a cooperative role in sporulation (Shaulsky and Loomis 1993). We proposed that all the cells in a developing aggregate have an initial tendency to become pre- 
spore cells but once a critical proportion of prespore cells is produced, the rest of the cells become prestalk. The tendency to become prespore cells is retained in the prestalk cells, and prespore cells suppress this tendency by producing and secreting an inhibitor of prespore differentiation to which they themselves are resistant (Loomis 1993; Shaulsky and Loomis 1993). Another mechanism of intercellular communication was inferred from the expression of a spiA::lac $Z$ gene fusion in sporulating cells during culmination. As the stalk tube elongates down through the prespore cell mass, a wave of spiA::lacZ expression propagates from the top of the sorus down (Richardson et al. 1994). Expression of spiA can also be induced by addition of 8 -Br-cAMP to cells dissociated at the culmination stage and shaken in buffer (Richardson et al. 1991). It was therefore proposed that prestalk cells signal the initiation of sporulation, probably by activating the cAMP-dependent protein kinase A (PKA).

Genes that affect differentiation in Dictyostelium have been cloned on the basis of sequence similarity to homologous genes in other organisms, but cloning of novel genes in the cell-type divergence pathway has required a different approach (Loomis et al. 1994). Random mutagenesis by plasmid insertion allows us to screen for morphologically aberrant strains and to subsequently clone the disrupted genes. This approach, referred to as restriction enzyme-mediated integration (REMI), involves electroporation of cells with linear vector DNA carrying a selectable marker, together with a restriction endonuclease that produces ends compatible to those of the linear vector (Kuspa and Loomis 1992). The enzyme directs integration of the plasmid into cognate restriction sites. Transformants are then visually screened for developmental defects after growth on bacteria as a source of nutrients. Mutants that are blocked at a certain stage in development can be mixed with wild-type cells to find ones that will then progress past the developmental block. These mutants are by definition cooperative (non-cell autonomous) and are suspected to have defects in intercellular communication.

Here we describe a mutant in cell-type divergence that suffered an insertion in the $\operatorname{tag} B$ locus. The gene has a unique structure, combining features of both serine proteases and of ATP-binding transporters of the multidrug resistance (MDR) family. $\operatorname{tag} B$ null cells are blocked at the tight aggregate stage of development and fail to differentiate as PST-A cells. Progression through the morphogenetic stages can be restored by cooperation with wild-type cells, but the block to PST-A development cannot be rescued. The results led us to propose a model in which a primary prestalk population (PST-I) is formed from which PST-A cells can then develop. Established PST-A cells induce remaining PST-I cells to differentiate as PST-O cells. This specialization is essential for further development of the fruiting body. The structure of the $\operatorname{tag} B$ gene implies that one of the signals emanating from PST-A cells could be a peptide that is processed by the protease part of the predicted TagB protein and secreted via the MDR homology transporter. This notion may provide a clue as to the processing and secretion of peptide hormones in other systems.

\section{Results}

Mutants in $\operatorname{tag} B$ were found in a screen of BamHI-REMI transformants as cells that develop normally until the tight aggregate stage but fail to develop further. Figure 1 compares the wild-type strain, which forms fruiting bodies after $24 \mathrm{hr}$ of development, with $\operatorname{tag} B^{-}$mutants that do not develop past the tight aggregate stage.

Insertions in the tagB locus result in lack of expression

Genomic $\operatorname{tag} B$ DNA was cloned from the mutant strain AK228, and probes were made from regions flanking the insertion site. The probes were used to map the gene to chromosome 4 (position 5.2) (Kuspa and Loomis 1994) and to clone the rest of the gene from genomic DNA sublibraries as well as from a cDNA library and by inverse PCR. A map of the $\operatorname{tag} B$ region in Figure 2a shows the $\operatorname{tag} B$ gene and two additional loci that cross-hybridize with several of the $\operatorname{tag} B$ probes. These loci, $\operatorname{tag} C$ and $\operatorname{tag} D$, are located within $20 \mathrm{~kb}$ of $\operatorname{tag} B$. Probes that hybridize with $\operatorname{tag} B$ but not with the other two genes were also found (Fig. 2a). Homologous recombination with the BgIII fragment around IS228 was used to recapitulate the mutation in a fresh host strain and an additional allele was generated in a different host by homologous recombination with the insertion placed $1.2 \mathrm{~kb}$ downstream, at IS517 (Fig. 2a). Figure 2b shows a Southern blot analysis of DNA from wild-type cells and from a $\operatorname{tag} B^{-}$mutant (517) with a probe that preferentially recognizes $\operatorname{tag} B$ (probe $\mathrm{B}$ ) and a probe that recognizes $\operatorname{tag} C$ and $\operatorname{tag} D$ as well (probe A). The data indicate that the insert into IS517 disrupted the $\operatorname{tag} B$ gene but not the other two. Insertions at both IS228 and IS517 resulted in similar morphological phenotypes and were identical in most of the physiological parameters. The IS228 insertion involved a complex genetic event that consisted of a small deletion in the $\operatorname{tag} B$-coding region and an insertion of uncharacterized DNA; therefore, all the experiments re-
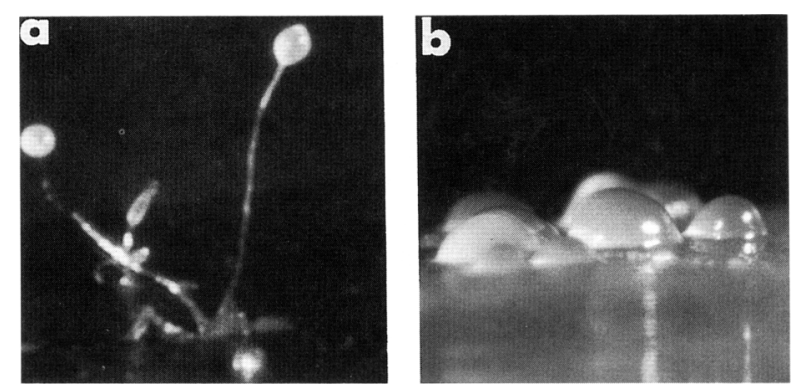

Figure 1. Morphological arrest of $\operatorname{tag} B^{-}$mutant at the tight aggregate stage of development. Wild-type $(a)$ and $\operatorname{tag} B^{-}$mutant (b) cells were washed from the nutrient source and developed on filters for $36 \mathrm{hr}$. 
a

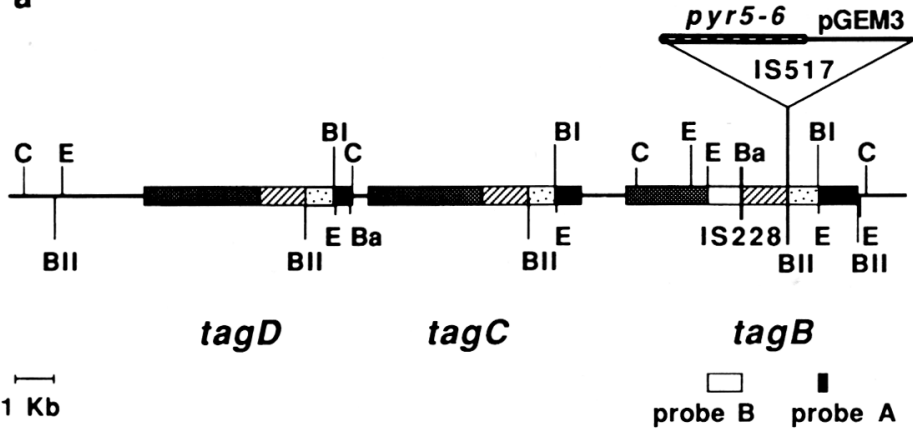

C

wild type

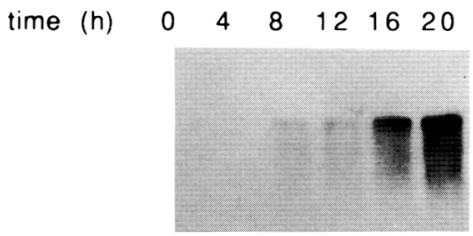

probe $B$ probe $A$

$\operatorname{tag} B$ mutant

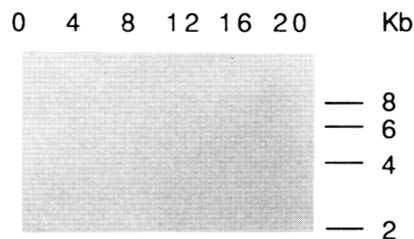

b

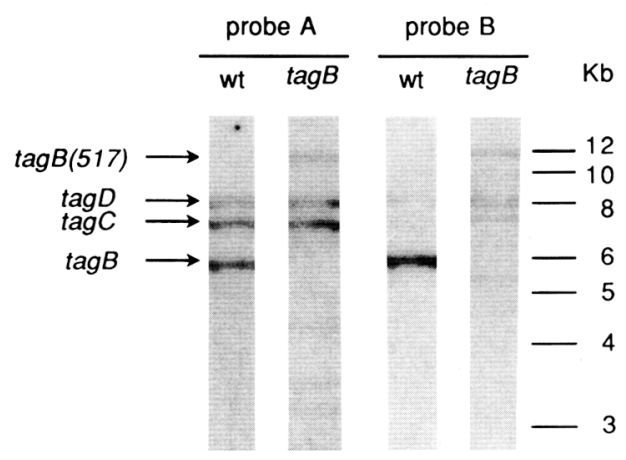

d

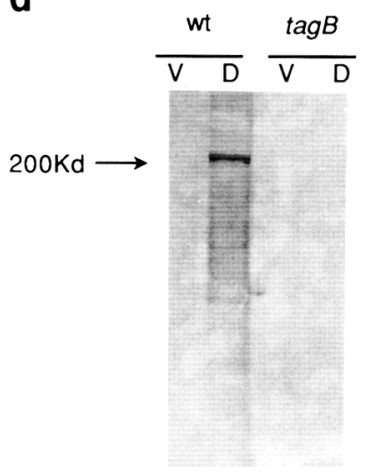

Figure 2. Insertional mutation in $\operatorname{tag} B$ results in lack of expression. $(a)$ Map of $\operatorname{tag} B$ and the two closely related genes $\operatorname{tag} C$ and $\operatorname{tag} D$. The original REMI disruption of $\operatorname{tag} B$ occurred at IS228. The insert into IS517 (shown to scale) was generated by homologous recombination of pCEM 3 plasmid DNA that contained $2.1 \mathrm{~kb}$ of $\operatorname{tag} B$ genomic DNA around IS517 and the pyr5-6 gene as selectable marker. The predicted coding region of $t a g B$ is shown in thick boxes and the filled pattern indicates cross-hybridization between the three genes. Boxes at the bottom represent a unique probe (probe B, empty box) and a redundant probe (probe A, full box). Restriction sites: (Ba) BamHI; (BI) BglI; (BII) BglII; (C) ClaI; (E) EcoRI. (b) Genomic DNA from wild-type and from tag $B$ mutant cells was digested with $\mathrm{Cla}$ I and resolved by electrophoresis through a $0.8 \%$ agarose gel. Southern blots were hybridized with the redundant probe $\mathrm{A}$ (see Fig. 2a) to visualize the three genes. The blots were later stripped and reprobed with probe B (see Fig. 2a) to visualize tagB. Locus names are indicated on the left; size standards are indicated on the right (kilobases). (c) Polyadenylated RNA was prepared from wild-type and from $\operatorname{tag} B$ mutant cells at different stages of development as indicated. RNA was resolved by electrophoresis through a $1.0 \%$ agarose gel containing formaldehyde. Northern blots were hybridized with probe B (see Fig. 2a). Size standards are indicated on the right (kilobases). (d) Total protein was prepared from vegetative cells (V) or from wild-type migrating slugs (wt) and from tag $B$ mutant aggregates after $48 \mathrm{hr}$ of development on agar plates (D). Protein $(10 \mu \mathrm{g} / \mathrm{lanc})$ was resolved by electrophoresis through a $6 \%$ polyacrylamide gel containing SDS and electrotransferred to a nitrocellulose membrane. Western blots were reacted with an anti-peptide antibody for TagB and with a secondary, alkaline-phosphatase-conjugated antibody and developed with NBT and BCIP. The size marker is indicated on the left (kilodaltons).

ported here were performed with strains in which the insertion occurred at IS517.

Probes specific to $\operatorname{tag} B$ were used to determine the size and the developmental regulation of the mRNA. Figure $2 c$ shows Northern blots of RNA prepared from wildtype and $\operatorname{tag} B^{-}$mutant cells at various stages of development. mRNA of $6.5-7.0 \mathrm{~kb}$ was first observed after 8 $\mathrm{hr}$ of starvation and continued to accumulate throughout development in the wild-type strain, but was not detected in the $\operatorname{tag} B^{-}$mutant (Fig. 2c). An antibody was raised against a synthetic peptide from the predicted amino-acid sequence of one of the regions in $\operatorname{tag} B$ that did not cross-hybridize with $\operatorname{tag} C$ and $\operatorname{tag} D$. The antipeptide antibody revealed a protein of about $210 \mathrm{kD}$ in Western blot analysis of wild-type cells but not in $\operatorname{tag} B^{-}$ mutants (Fig. 2d). These results show that the insertion into IS517 resulted in lack of $\operatorname{tag} B$ expression at the mRNA and at the protein level.

\section{Mutants in tagB respond to intercellular signals but fail to produce DIF-1}

The onset of $\operatorname{tag} B$ expression occurs concomitantly with the beginning of cell-type divergence at the loose aggregate stage. The morphological arrest in the mutant is at the tight aggregate stage, just before tip formation by prestalk cells. To understand the role of $\operatorname{tag} B$ in cell-type divergence and tip formation, we examined the effects of the mutation on expression of the prestalk-specific gene $e c m A$ and the prespore-specific gene $\cot B$. The data in 
Figure 3a show that whereas the $\operatorname{tag} B^{-}$mutation did not alter $\cot B$ expression, accumulation of $e c m A$ mRNA was markedly reduced in the mutant. An apparent decrease in $\cot B$ and $e c m A$ mRNA levels can be observed in the 24-hr samples from wild-type cells but not in the mutants (Fig. 3a). This is because of reduced efficiency of RNA extraction from encapsulated spores and stalk cells in wild-type cells (Richardson and Loomis 1992; Shaulsky and Loomis 1993) and reflects the observation that $\operatorname{tag} B^{-}$mutants do not form spores and stalks. The continued accumulation of $\cot B$ and $e c m A$ RNA in the mutant cells shows that, in spite of the morphological arrest at the tight aggregate stage, $\operatorname{tag} B^{-}$mutants continue to progress along some developmental pathways.

The reduced accumulation of ecm $A$ RNA in the mutants suggested that prestalk development was impaired. Because $\operatorname{ecm} A$ expression can be induced by the natural morphogen DIF-1, we tested the possibility that $\operatorname{tag} B$ was involved in the ability of developing cells to respond to the morphogen. Addition of DIF-1 to wild-type cells in suspension, in the presence of $\mathrm{Ca}^{2+}$ ions and cAMP, results in increased accumulation of $e c m A$ and $e c m B$ RNA and decreased levels of the prespore marker D19 (Berks and Kay 1990). Fosnaugh and Loomis (1991) showed that accumulation of $\cot B$ mRNA was increased in the presence of cAMP and $\mathrm{Ca}^{2+}$ ions and decreased following addition of DIF-1. The data in Figure $3 \mathrm{~b}$ show that $\operatorname{tag} B^{-}$ mutants were able to respond normally to the addition of DIF- 1 in the presence of CAMP and $\mathrm{Ca}^{2+}$ ions by accumulating higher levels of ecm $A$ mRNA and reduced levels of $\cot B$ mRNA. These experiments also revealed that the mutant cells respond normally to cAMP and to $\mathrm{Ca}^{2+}$ ions by the accumulation of $\cot B$ mRNA. DIF-1 breakdown in the $\operatorname{tag} B^{-}$mutants was also found to be unaltered relative to the wild-type strain (R.R. Kay, pers. comm.).

To quantify the effects of the mutation on development, we generated $\operatorname{tag} B^{-}$mutant strains that carry the $l a c Z$ gene under control of various cell-type-specific regulatory elements. Total enzyme activity was used to es- a

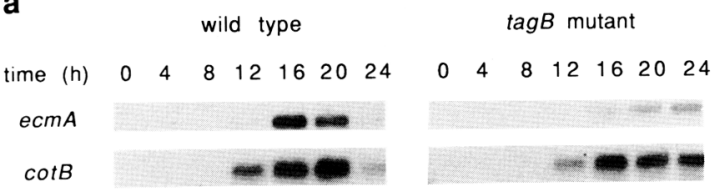

c

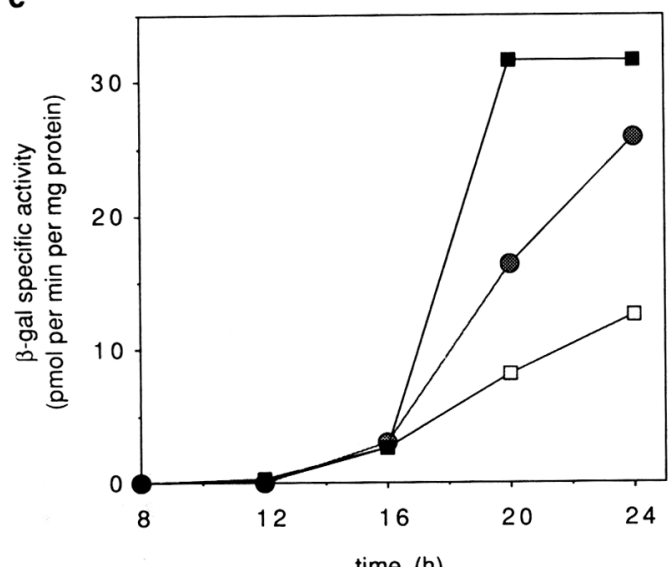

b

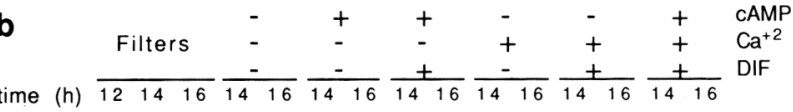

ecmA

$\cot B$

d

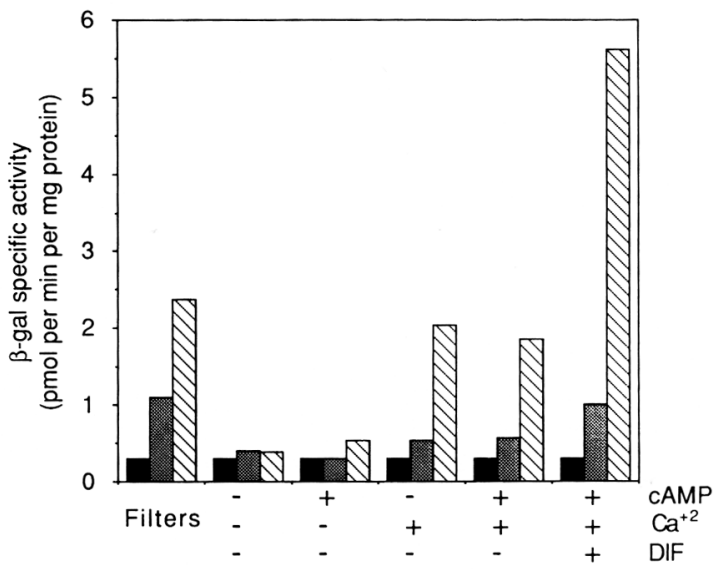

Figure 3. Response of $\operatorname{tag} B^{-}$mutants to extracellular morphogenic signals. $(a)$ Northern blot analysis of total RNA prepared from wild-type and from $\operatorname{tag} B^{-}$mutant cells at different stages of development as indicated. Blots were hybridized with a probe for ecm $A$, stripped, and reprobed for $\cot B$ as indicated. $(b) \operatorname{tag} B^{-}$mutant cells were developed on filters for $12 \mathrm{hr}$, collected, dissaggregated, and resuspended in buffer. Cells were shaken in suspension with supplements as indicated and samples were collected 2 and $4 \mathrm{hr}$ later $/ 14$ $\mathrm{hr}, 16 \mathrm{hr}$, respectively). Total RNA was prepared from the samples and from cells that were developed on filters without supplements. Northern blots were prepared and hybridized with probes for ecmA and $\cot B$. Supplements: (cAMP) $20 \mu \mathrm{M} / \mathrm{hr} ;\left(\mathrm{Ca}^{2+}\right) 0.2 \mathrm{mM} \mathrm{CaCl}$; (DIF) $50 \mathrm{~nm}$ DIF-1/hr. (c) Cells were mixed at 1:1 ratios and developed on filters. Samples were collected at the indicated time points and resuspended in buffer containing $1 \%$ Triton X-100. Cell-free extracts were incubated with ONPG, and $\beta$-galactosidase activity was measured by absorbance at $420 \mathrm{~nm}$. Results were normalized to protein concentration and to reaction time. ( $\square$ ) $\operatorname{tag} B^{-} e c m A:: l a c Z$ mutant cells mixed with $\operatorname{tag} B^{-}$mutant cells without the reporter gene; (O) wild-type $e c m A:: 1 a c Z$ cells mixed with wild-type cells without the reporter gene; ( $) \operatorname{tag} B^{-}$ecm $A:: \operatorname{lac} Z$ mutant cells mixed with wild-type cells without the reporter gene. $(d) \operatorname{tag} B^{-}$ ecm $A:: 1 a c Z$ cells were developed on filters or in suspension with supplements as in $b$. $\beta$-Galactosidase activity was measured as in $c$. (Solid bars) 12-hr cells; (stippled bars) 14-hr cells; (hatched bars) 16-hr cells. 
timate the effects of extracellular signals on specific gene expression. The results in Figure $3 c$ show that the enzyme activity detected in the $\operatorname{tag} B^{-}$ecm $A:: \operatorname{lac} Z$ reporter strain (open boxes) was consistent with the expression pattern of the endogenous $e c m A$ mRNA, and was about fourfold reduced compared to the parental wild-type strain (circles). Mixing $\operatorname{tag} B^{-}$ecm $A:: 1 a c Z$ cells with unlabeled wild-type cells resulted in normal overall morphology during filter development (see below) and increased the enzyme activity in the mutant strain back to the wild-type level of expression (Fig. 3c, solid boxes). Addition of DIF-1 in the presence of cAMP and $\mathrm{Ca}^{2+}$ to shaking suspensions of the $\operatorname{tag} B^{-} e c m A:: 1 a c Z$ cells induced the enzyme activity about fivefold as well (Fig. $3 \mathrm{~d}$ ), indicating that the increased level of ecmA expression in the mixed aggregate may be fully attributed to DIF-1 production by the wild-type cells. The effect of DIF-1 on the increase in ecm $A:: 1 a c Z$ expression was due in part to a twofold increase in the number of cells stained by X-gal (data not shown). It is impossible to determine whether the increased number of positively stained cells was attributable to recruitment of undifferentiated cells to the prestalk pathway, or to increase of enzyme activity in already existing prestalk cells above the threshold of detection. On the basis of the results presented in Figure 3 we conclude that $\operatorname{tag} B^{-}$mutants have developed the ability to respond to CAMP, $\mathrm{Ca}^{2+}$ and DIF-1, indicating that the response to extracellular signals is not likely to be the primary defect induced by the mutation.

The possibility that $\operatorname{tag} B^{-}$mutants were defective in production of DIF-1 was also tested. In wild-type cells, DIF-1 starts to accumulate at the tight aggregate stage and maximal levels are observed at the finger stage, $\sim 15-20 \mathrm{hr}$ after the initiation of development, whereas vegetative cells contain no measurable amounts of DIF-1 (Brookman et al. 1987). Hexane extracts were therefore prepared from wild-type cells and several $\operatorname{tag} B^{-}$cell lines at the vegetative stage and after $17 \mathrm{hr}$ of development. The extracts were tested for their ability to induce vacuolization of V12M2 cells in submerged cultures (Brookman et al. 1987). The results were normalized to the number of cells extracted and compared to the effect of adding $200 \mathrm{~nm}$ pure synthetic DIF-1 to the test plates. Table 1 shows that extracts from $1.4 \times 10^{7}$ developing

Table 1. DIF-1 synthesis in wild-type and tagB $\mathrm{B}^{-}$mutants

\begin{tabular}{lc}
\hline $\begin{array}{l}\text { Hexane extract } \\
\left(1.4 \times 10^{7} \text { cells }\right)\end{array}$ & Percent vacuolization ${ }^{\mathrm{a}}$ \\
\hline Wild type, vegetative & 0 \\
Wild type, 17-hr development & $11 \pm 2$ \\
tagB $B^{-}$mutant, vegetative & 0 \\
tagB $B^{-}$mutant, 17-hr development & $0.2 \pm 0.3^{\mathrm{b}}$ \\
$200 \mathrm{nM}$ purified DIF-1 & $26 \pm 4$
\end{tabular}

${ }^{a}$ Average \pm standard deviation of three independent experiments.

${ }^{\mathrm{b}}$ Average \pm standard deviation of six independent $\operatorname{tag} B^{-} \mathrm{mu}-$ tant strains. wild-type cells contained the equivalent of 100 nM DIF-1, but extracts prepared from the same number of $\operatorname{tag} B^{-}$ mutant cells contained no measurable amounts of DIF-1.

The results in Figure 3 and Table 1 indicate that $\operatorname{tag} B^{-}$ cells have the ability to respond to DIF-1 but fail to produce it. Wild-type cells were able to rescue the effects of the $\operatorname{tag} B^{-}$mutation on general morphology and on ecm $A$ expression, presumably by secreting an exogenous factor that $\operatorname{tag} B^{-}$mutants fail to produce or secrete themselves. If DIF-1 was that factor, it would be expected to rescue the morphological defect in $\operatorname{tag} B^{-} \mathrm{mu}-$ tants. To test that possibility, $\operatorname{tag} B^{-}$mutant cells were developed on filters and DIF-1 was added at a range of concentrations from 50 to $200 \mathrm{nM}$ at various time points after starvation or in $50 \mathrm{~nm}$ doses at 2-hr intervals starting from $8 \mathrm{hr}$ of development. Added DIF-1 caused an increase in ecmA::lacZ expression, but none of the conditions was sufficient to induce sporulation or any significant changes in the overall morphology (data not shown). We conclude that the defect in DIF-1 production in the mutant does not account for the developmental arrest and is probably due to a dependent sequence (epistasis) effect rather than a direct consequence of the $\operatorname{tag} B$ gene disruption.

\section{Failure of $\operatorname{tagB}^{-}$mutants to develop as PST-A cells} reveals a new type of prestalk cells

The same lac $Z$ reporter strains were used to follow the distribution of all prestalk cells by X-gal staining of pure populations of mutant cells or in mixed populations with cqual numbers of wild-type cells. Figure 4a shows that prestalk cells were sorted to the upper part of the tight aggregates in pure $\operatorname{tag} B^{-}$mutant populations, a normal pattern for the tight aggregate stage at which development was arrested. When mixed with wild-type cells, $\operatorname{tag} B^{-}$mutants were able to cooperate and participate in formation of a mature fruiting body (Fig. 4), but a significant difference from the wild-type prestalk pattern was observed in such mixed populations. The mutant prestalk cells were not found in the tip of the anterior region of the finger stage (Fig. 4b) and were also absent from the stalk of the mature fruiting body (Fig. 4c), indicating a defect in differentiation of PST-A cells. Two possible explanations could account for the lack of staining in the tip and in the stalk of the mixed structure: Either the $\operatorname{tag} B^{-}$mutant cells were physically excluded from the tip and from the stalk, or they were present in the tip but did not express the ecmA::lacZ gene. To distinguish between the two possibilities we constructed a $\operatorname{tag} B^{-}$mutant strain expressing $\operatorname{lac} Z$ under the vegetative actin 15 promoter. Figure $4 \mathrm{~d}$ shows that all of the cells were stained in a pure population of $\operatorname{tag} B^{-}$mutants carrying act $15:: 1 a c Z$. In the mixed population, X-galstained cells were absent from the tip (Fig. 4e) and from the stalk (Fig. 4f), indicating that the mutant cells were excluded from those regions.

Mutant $\operatorname{tag} B^{-}$cells appear to have a cell-autonomous defect in PST-A differentiation. It was interesting to know whether the other prestalk subpopulation, namely 
Figure 4. Prestalk specialization of $\operatorname{tag} B^{-}$mutants. lacZ-expressing cells were developed on filters for 16 and $24 \mathrm{hr}$ in pure populations or mixed at $1: 1$ ratios with wild-type cells without the reporter gene. $\operatorname{tag} B^{-} e c m A:: 1 a c Z$ cells were developed as a pure population for $24 \mathrm{hr}(a)$ or mixed with wildtype cells for $16(b)$ and $24 \mathrm{hr}(c)$. tag $B^{-}$act $15:: 1 a c Z$ cells were developed as a pure population for $24 \mathrm{hr}(d)$ or mixed with wild-type cells for $16 \mathrm{hr}(e)$ and $24 \mathrm{hr}(f)$. tagB $B^{-}$pst $O:: 1 a c Z$ cells were developed as a pure population for 24 $\mathrm{hr}(\mathrm{g})$ or mixed with wild-type cells for $16 \mathrm{hr}(\mathrm{h})$ and $24 \mathrm{hr}(\mathrm{i})$. Wild-type pst $O:: 1 a c Z$ cells were developed as a pure population for $16 \mathrm{hr}(j)$ and $24 \mathrm{hr}$ $(k)$. Samples were fixed, permeabilized, and stained with X-gal. lacZ-Expressing cells are blue.

PST-O, was also affected. In wild-type aggregates pstO::lacZ staining is apparent in scattered cells throughout the mound (Early et al. 1993), but in $\operatorname{tag} B^{-}$ mutants we observed no staining until 20-24 hr after the initiation of development. Figure $4 \mathrm{~g}$ shows that in pure populations of $\operatorname{tag} B^{-}$mutant cells carrying pst $O:: 1 a c Z$, most aggregates contained no stained cells whereas a few had one or two. When mixed with wild-type cells, the staining pattern of the mutant $\operatorname{tag} B^{-}$pstO::lacZ after 16 and $24 \mathrm{hr}$ of development (Fig. $4 \mathrm{~h}$ and $\mathrm{i}$, respectively) was indistinguishable from that of the wild-type pst $O:: 1 a c Z$ strain (Fig. $4 j$ and $k$, respectively). Because PST-O cells were normally distributed in the mixed aggregates but were absent in mutant aggregates, we conclude that PST-O development is dependent on $\operatorname{tag} B$ in a cooperative (non-cell-autonomous) manner and is probably dependent on the presence of PST-A cells.

By use of the ecmA::lacZ marker we found that $\operatorname{tag} B^{-}$mutants are able to differentiate and sort as prestalk cells (Fig. 4a) but fail to develop as PST-A cells (Fig. 4b,c) or as PST-O cells (Fig. 4g). This observation indicates the existence of a previously unrecognized type of prestalk cells from which the two other types may develop. We propose the name PST-I to describe these cells.

The primary defect in prestalk differentiation of $\operatorname{tag} B^{-}$ mutants is cell autonomous and is consistent with a lack of the PST-A subpopulation. We tested RNA preparations enriched for prespore and prestalk cells and found that the cell-type specificity of $\operatorname{tag} B$ RNA expression is supportive of that notion. Cell-type-specific RNA was prepared by centrifugation of dissociated wild-type cells prepared from slugs and extraction of RNA from the prestalk and prespore fractions. Figure 5a shows a Northern blot of RNA from the fractions, hybridized to probes for $e c m A$ and for $\cot B$ as cell-type-specific markers to estimate the degree of purification. The $\operatorname{tag} B$-specific probe in Figure $5 \mathrm{~b}$ shows that the mRNA is enriched in the prestalk fraction as much as the ecmA marker.

tagB contains sequences that are homologous to serine protease and to MDR transporter genes

Additional insight into the possible mechanism of action of the $\operatorname{tag} B$ gene in development was gained from the primary sequence of the predicted protein shown in Figure $6 a$. The $\operatorname{tag} B$ gene contains an open reading frame
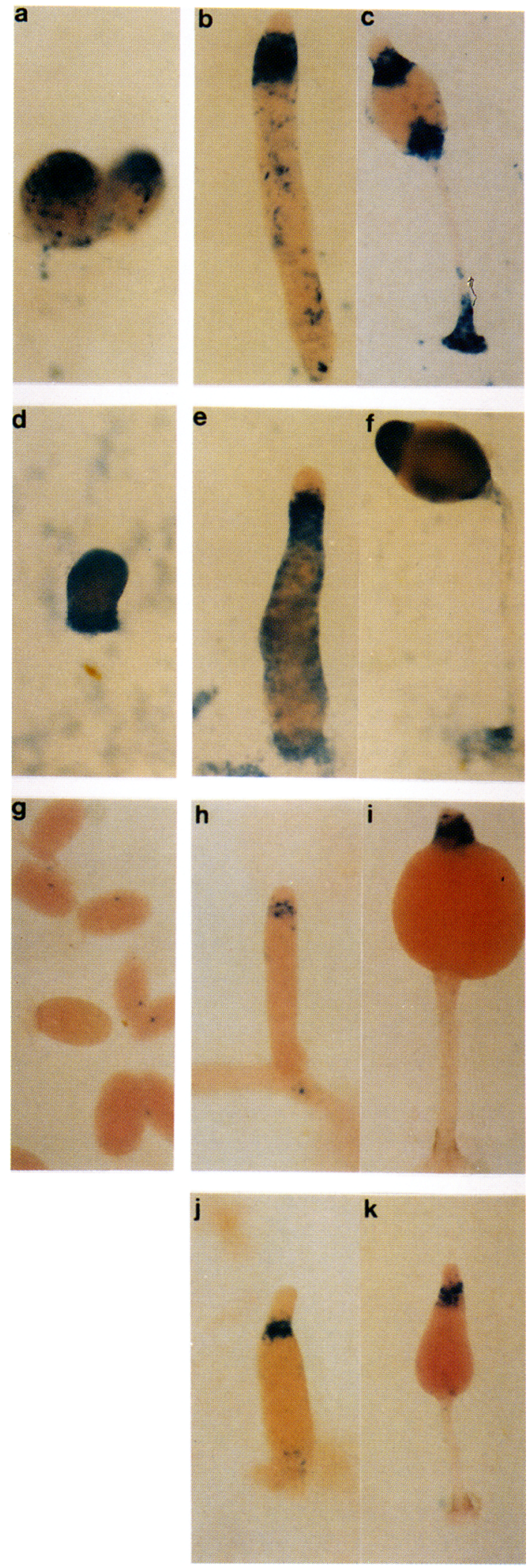

(ORF) of 5715 bp without any introns and is separated from the $\operatorname{tag} C$ gene by about $1 \mathrm{~kb}$ (see map in Fig. 2). The 


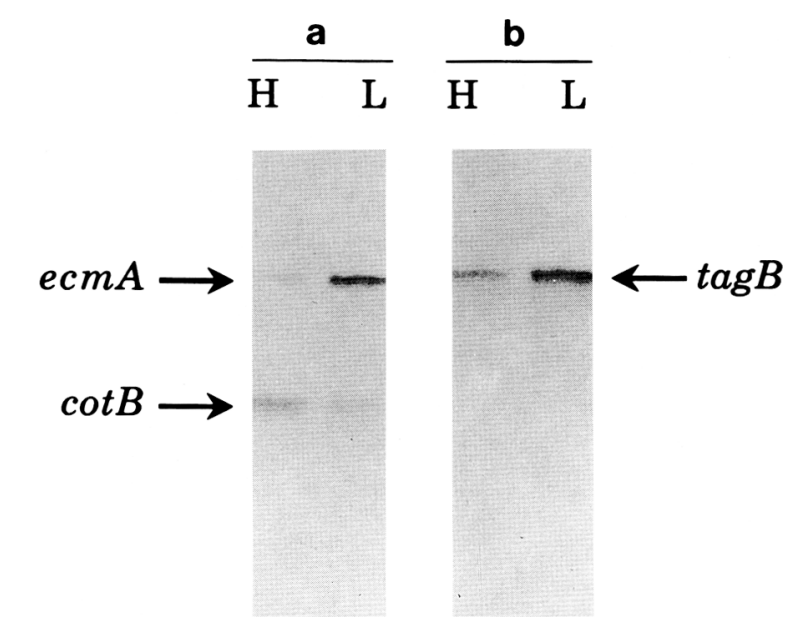

Figure 5. Cell-type specificity of $\operatorname{tag} B$ gene expression. Wildtype cells were developed on agar plates for $48 \mathrm{hr}$ and slugs were collected and dissaggregated. Cells were centrifuged through Percoll gradients, and two fractions were collected separately. The lower fraction heavy $(\mathrm{H}) \mid$ is enriched with prespore cells and the upper fraction [light (L)/ is enriched with prestalk cells. Northern blots were made with total RNA from the respective fractions; ecm $A$ and $\cot B$ probes were used to determine the level of enrichment of prestalk and prespore cells, respectively $|a|$, and probe B (Fig. 2a) was used to detect $\operatorname{tag} B$ RNA $|b|$ as indicated.

upstream region and ORF were cloned into a plasmid carrying a G418-resistance marker. Upon transfection of the plasmid into $\operatorname{tag} B^{-}$mutants, G418 ${ }^{\mathrm{r}}$ colonies developed that regained the ability to form normal fruiting bodies (data not shown). This result indicates that the sequenced region is sufficient to complement the $\operatorname{tag} B^{-}$ mutation and can therefore account for the complete sequence of the gene. The calculated molecular weight of the TagB protein is $210 \mathrm{kD}$, consistent with the measured size found by Western blot analysis (Fig. 2d). Comparison of the TagB sequence against several protein data bases using the BLAST algorithm (Altschul et al. 1990) revealed two major domains of homology to distinct gene families. In the amino-terminal half of TagB, we found sequence similarity to the essential components of the active site in a family of serine proteases (Fig. 6b). The similarities are in the predicted charge relay system that includes $\mathrm{D}^{387}, \mathrm{H}^{432}$, and the active serine $\mathrm{S}^{695}$, as well as $\mathrm{N}^{538}$ in the predicted orientation determination pocket (Kraut 1977; Vos et al. 1989). In the carboxy-terminal half of TagB we found extensive similarity to proteins from the MDR family of ATP-dependent transporters (for review, see Ames 1986; Pastan and Gottesman 1991). Sequence similarity was found in the bipartite ATP-binding site (Fig. 6b) and in the six transmembrane domain (data not shown) as well as in the overall hydrophobicity pattern of TagB that indicated a plausible six transmembrane domain between amino acids 10001400 (Fig. 6c). A hydrophobic region that could serve as a signal sequence for membrane insertion was found in the amino terminus of TagB. Our search of the data base did not reveal other examples of proteins carrying a fusion of these two regions. On the basis of the homology to serine proteases and to ATP-binding transporters, we suggest that TagB could be a membrane protein involved in proteolytic processing and transport of a peptide.

\section{tagB allows cooperation of prestalk and prespore cells during culmination}

Microscopic examination of dissociated cells from $\operatorname{tag} B^{-}$aggregates revealed no spores or stalk cells (data not shown). The lack of spores is demonstrated in Table 2 where detergent treatment of developed $\operatorname{tag} B^{-}$cells resulted in a complete loss of viability, showing that $<1$ in $5 \times 10^{7}$ mutant cells had sporulated. Interestingly, $\operatorname{tag} B^{-}$cells can develop into spores in mixed aggregates with wild-type cells (Table 2) indicating that, like the PST-O defect, the sporulation deficiency is cooperative (non-cell autonomous). This situation is similar to another prestalk specific defect, namely that which results from over expression of ecmA::Rm. In the latter, a mutated regulatory subunit $(\mathrm{Rm})$ of the cAMP-dependent protein kinase $\mathrm{A}$ is expressed under the ecmA promoter such that prestalk cells are expected to have reduced levels of PKA activity, whereas prespore cells are not affected directly (Harwood et al. 1992). ecmA::Rm cells develop normally until the finger stage, at which they arrest. Spores and stalks are not produced when these cells are developed as pure populations, but sporulation of the mutant cells can be induced by cooperation with wild-type cells (Table 2) as in the case of $\operatorname{tag} B$ mutant cells. In the mixed aggregates, ecm $A:: R m$ cells fail to enter the PST-A region and do not participate in stalk formation. We mixed $\operatorname{tag} B^{-}$mutants with ecm $A: \because R m$ cells and examined their ability to form spores. The cells in such experiments formed mixed aggregates and developed to the finger stage, but neither of them sporulated, despite their ability to sporulate in the presence of wildtype cells (Table 2). This experiment indicates that both tag $B^{-}$and ecmA $:: R m$ cells are deficient in the same pathway that leads to differentiation of PST-A cells, which are subsequently required for development of PST-O cells as well as for sporulation.

\section{Discussion}

The primary defect in $\operatorname{tag} B^{-}$mutants appears to be a complete lack of differentiation of PST-A cells that cannot be overcome even by the presence of wild-type cells in mixed aggregates. This cell-autonomous phenotype may result from a failure to remove an endogenous inhibitor produced in early prestalk differentiation. The serine protease homology domain of TagB suggests that it may be responsible for proteolytic inactivation of an inhibitor protein, whereas the MDR transporter homology suggests that it may remove an inhibitor by secreting it from the cell. In fact, TagB may carry out both functions by generating peptides and then transporting them out of the cells. This raises the possibility that the se- 
Figure 6. Sequence analysis of the $\operatorname{tag} B$ gene. $(a)$ The complete amino acid sequence was deduced from the nucleotide sequence of cDNA and genomic DNA clones (GenBank accession no. U20432). Underlined sequences indicate regions of homology to serine protease and to ATP-dependent transporters of the MDR family. (See details below.) (b) Comparison of TagB predicted amino acid sequence to the serine protease proteinase $\mathrm{K}$ (endopeptidase $\mathrm{K}$ precursor from Tritirachium album, EC 3.4.21.64, accession no. P06873 in PIR data basel and to the ATP-dependent transporter MDR 1 protein (MDRl) from Chinese hamster, Cricetulus griseus, accession no. A38696; A27126 in PIR data base). Underlined sequences are essential for activity of the respective proteins. Numbers indicate the first and the last amino acid of the compared sequence, vertical bars indicate sequence identity, columns indicate sequence similarity, horizontal bars indicate gaps between similar regions. (NB) Nucleotide binding fold of MDR. (c) Hydropathy chart of the predicted amino acid sequence for TagB. Numbers above the box indicate position in the amino acid sequence and numbers on the left indicate relative hydrophobicity. Note the hydrophobic region at the amino-terminus indicating a predicted signal sequence and the hydrophobic regions between amino acids 1000 and 1400 indicating a predicted six transmembrane domain. a

1 MEFOFSSPSK IFLSSSVILI LIFIGIKFEL LEDTNSNRND KFNNIINRFI NYNIDDSIYK NX0000OFSN KIYSNEKKIL BO

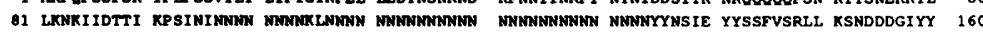
161 DOYOSKYKKN HYIVORKDRI NDETREOLKE FLIGTOITIL KEOPFKSHIV HYIPHDSFLV FMTKEQSVLL SSKEWISWIG 240 241 EKEPSNKIHL NYHEKSIGYP VYIILSGSTN SLIQRWENTL NSILTSYNSK VKLTLINOKK LKSIVYCNDE SPSSSSSSSC 320 321 SLIGSEKIVY KMISEOSESN YIERSEKLOT ANRLSPTVIF GTKDKLVNND RIDIPLRGKG QILSIADTGL DGSHCFTSDS 400 101 KYP IPFNOWN ENHRKVVTYI TYHDNEDYVN GHGTHVCGSA AGTPEDSSWA ISSFSGLATD AKIAFYDLSS GSSEPTPPED 480

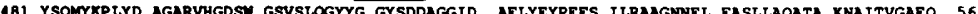
181 YSOMV 561 TAHWTWSOA LETYOFSDNA NFORPCLFDK KYCNYTTAKC CSEVSNVXGL QLCCPASTKO NASDSFTIQP OFYNENNMGS 640 641 FSSKGPTHG RLKPDIVAPG EYITSARSNG ENSTDOCGDG SLPNANGLMS ISGTSMATPL ATAATTILRQ YLVDGYFPTG 720 721 ESVEETLLP TGSLOL B01 IGGLGKNOKA TEWREDSLSS GLNKSYCFTY KPSSSSSGSG GGGGTPRIVA TLWWDPPSY SGAKFNLWNN LDLLLLNSDD 880 BB1 DSIITIGNSG GSLOPAGKVA OPDTLNNVEG IIINPTKAMN YKFTIAGTNV PIGPOKFSFV FHGENGQFDW ADSCPQCVDG 960 961 VOFPCIITNG IGIQSCGSDL LWTKCIVQSC NEGYNYNSLK NTCDKFLSYN YIIIIVAGGT MVLIILLLMW IKYOEYKESK 1040 1011 RDSFRRFDDG TGIFVRPKDK DAKVTPPDLY NLVSPFIIEL TIATACSLVA TMASILOPFY IGNIVNNIPT TKSIGEFKSD 1120 1121 FIIIFILAFI EFLFTNVGSW ISGIVNEKMV MRLONKVFRA LIAQDMGFFQ RNNSALLMNV LIVDTPMLRS ALTGILLSIA 1200 1201 TGVCKLVGSL VFIFTISWKL SLAFFMAVI LGLVTQIQSQ FTKRLTRQLL FHNSKASQHG TESLTNMHVV TNYCKQEKEM 1280 1291 VKYSDQLANV FITARKLIIT NTFAGTGKWL LIESLTFVIL YFSAYLVIOK OFTVGLMISF SLYIGYVVDA SSSLFGVYVS 1360 1361 YIQCLASATR VFMILRSAPR KRTTLEEEEA DRLAGLSGGG GGGGDNGDDK KDKONIENGK DVLPSNIITP IDNVENSNGK 1440 2441 ODDPWYYMYW IGNLOYSEO DCVSTVADST VGLTKRELKK OKEKEOKEYF KOTGISVAET PTFLPSSYTE LECRGEIEF 1520 1521 MVVSRYPTR PDOY

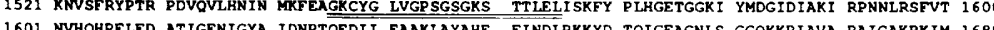
1601 .

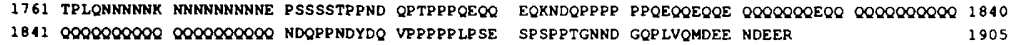

b

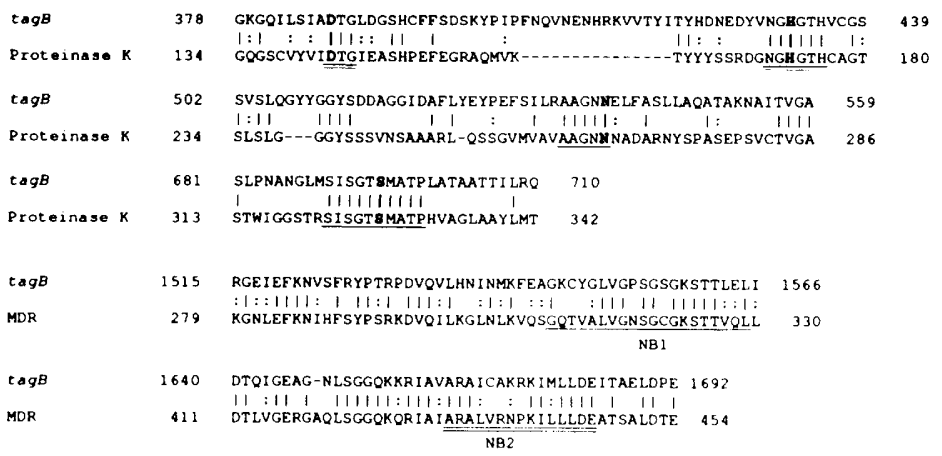

C

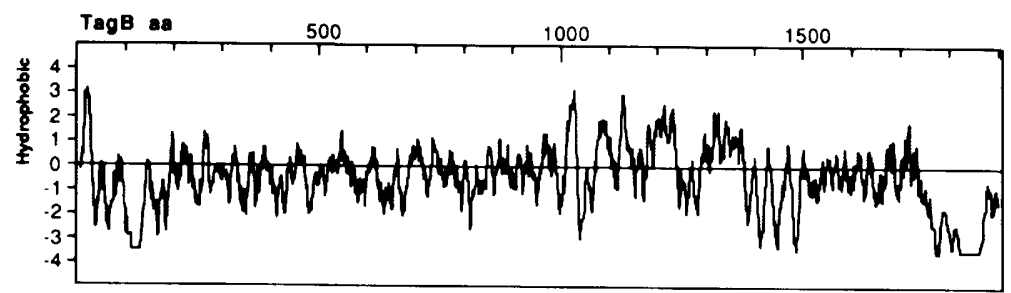

creted peptides could function as signaling molecules, controlling the differentiation of other cell types in the aggregate.

Allopathic systems that combine proteolytic processing and membrane transport of the peptide products have been described in other organisms. In Saccharomyces cerevisiae, the mating pheromone a-factor is synthesized as a 36- or 38-amino-acid precursor form the MFA1 and MFA2 genes, respectively (for review, see Michaelis 1993). Following proteolytic processing by yet-undefined proteases, isoprenylation by the gene products of RAM1 and RAM2, and methylation by the STE14 gene product, the mature pheromone is transported across the plasma membrane and out of the cell via the STE6 gene product that is a member of the MDR gene family (Kuchler et al. 1989; McGarth and Varshavsky 1989|. In mammalian cells, foreign proteins are fragmented by proteolytic ac- tivities in the cytoplasm, and the products are transported into a pre-Golgi compartment via a heterodimeric

Table 2. Cooperative sporulation

\begin{tabular}{ccc}
\hline \multicolumn{2}{c}{ Strains $(\%)$} & Mutant spores $(\%$ of total) \\
\hline Wild type & $\operatorname{tag}^{-}$mutant & \\
0 & 100 & 0 \\
10 & 90 & 52 \\
50 & 50 & 36 \\
90 & 10 & 9 \\
Wild type & $e c m A:: R m$ & 0 \\
0 & 100 & 48 \\
50 & 50 & \\
$\operatorname{tag} B^{-}$mutant & $e c m A:: R m$ & 0 \\
50 & 50 & \\
\hline
\end{tabular}


membrane transporter of the MDR family that is composed of the TAP1 and TAP2 gene products (Townsend et al. 1985; Deverson et al. 1990; Monaco et al. 1990; Spies et al. 1990; Trowsdale et al. 1990). The peptides are then associated with major histocompatibility complex (MHC) class I proteins and presented on the cell surface. In Dictyostelium, the two functions are linked because in TagB the protease and the transporter homology domains are encoded by the same gene.

MDR genes are internally duplicated such that each gene product consists of two sets of a highly conserved bipartite ATP-binding domain and two sets of a lessconserved putative six transmembrane domain /Chen et al. 1986). The MHC transporters TAP1 and TAP2 are not internally duplicated, but the proteins associate in the membrane into a functional dimer (Spies et al. 1992). Likewise, $\operatorname{tag} B$ encodes a single putative six transmembrane domain and a single bipartite ATP-binding domain, indicating that it may also function as a dimer. TagB may form homodimers, or heterodimers with the proteins encoded by the cohybridizing genes $\operatorname{tag} C$ and $\operatorname{tag} D$. We have partially sequenced the $\operatorname{tag} C$ gene and find that the putative nucleotide binding domains of $\operatorname{tag} B$ and $\operatorname{tag} C$ are $\sim 90 \%$ identical and that the putative transmembrane domains are $\sim 60 \%$ identical (G. Shaulsky and W.F. Loomis, unpubl.). Thus, $\operatorname{tag} C$ may function as a transporter protein as well. Indeed, insertional inactivation of the $\operatorname{tag} C$ gene results in a phenotype that is almost identical to that of $\operatorname{tag} B^{-}$mutants (G. Shaulsky and W.F. Loomis, unpubl.). Although both $\operatorname{tag} B^{-}$and $\operatorname{tag} C^{-}$cells can differentiate into spores when they develop in mixed aggregates with wild-type cells, they do not form spores when mixed with each other in the absence of wild-type cells. Thus, both TagB and TagC appear to be required to gencrate the signal necessary for sporulation, as would be expected if $\mathrm{TagB}$ and $\mathrm{TagC}$ function in a heterodimer.

We found that in addition to the cell-autonomous lack of PST-A cell specialization, $\operatorname{tag} B^{-}$mutants exhibit defects that can be overcome by the presence of wild-type cells. Development of mixed populations showed that both sporulation and PST-O specialization of the $\operatorname{tag} B^{-}$ mutant cells were restored in aggregates containing wild-type cells. Therefore, wild-type cells produce signals that $\operatorname{tag} B^{-}$mutants can receive and respond to. These signals could be peptides that are produced and secreted by different dimers of TagB, TagC, and TagD in the wild-type PST-A cells, each combination producing a different signal. The cooperative failure of ecmA::Rm cells to sporulate and their inability to cooperate with $\operatorname{tag} B^{-}$mutants indicates that the signaling pathway involves the function of PKA in PST-A cells.

Prestalk differentiation of $\operatorname{tag} B^{-}$mutant cells was apparently normal during early development up to the time of developmental arrest. Induction of ecmA expression occurred at the normal time and mutant prestalk cells sorted to the top of the aggregate as would wild-type cells at that stage. In wild-type cells there are several subpopulations of prestalk cells, including PST-A cells that are defined by localization to the most anterior part of the prestalk zone (Jermyn et al. 1989; Williams et al. 1989) and PST-O cells that are defined by activation of specific regions in the ecmA promoter (Early et al. 1993). In pure populations of $\operatorname{tag} B^{-}$mutant cells, PST-O cell differentiation failed to occur. Therefore, PST-O cells could not account for the presence of ecmA::lacZ expressing cells in the developing $\operatorname{tag} B^{-}$mutants. Because $\operatorname{tag} B^{-} \mathrm{mu}-$ tants do not form PST-A cells either, we conclude that $\operatorname{tag} B$ defines an initial population of prestalk cells, namely PST-I, from which both PST-A and PST-O cells specialize. Because $\operatorname{tag} B^{-}$mutant cells do not accumulate DIF-1, PST-I cells can be defined as ecm $A$-expressing cells that develop independently of the prestalk morphogen but can respond to it by accumulating increased levels of ecmA RNA. PST-I cells are also sensitive to the effects of cAMP and calcium ions. Because PST-O specialization was cooperatively induced by wild-type cells, we propose that in normal prestalk differentiation, PST-O specialization is dependent on the presence of PST-A cells. We propose that following accumulation of the $\operatorname{tag} B$ gene product, some of the PST-I cells specialize and become PST-A cells that can produce a signal that induces yet unspecialized PST-I cells to become PST-O cells (Fig. 7). This model could account for proportioning of these prestalk cell types by a mechanism of lateral inhibition.

Following aggregate formation, prestalk cells sort to the top where a tip is formed. From the phenotype of $\operatorname{tag} B^{-}$mutants we learn that tip formation is dependent on the presence of PST-A cells, PST-O cells, or both. On the basis of the spatial localization of the cell types in slugs, PST-A cells are probably responsible for the tip, whereas PST-O cells define the base of the tip. PST-A cells subsequently form the stalk in culminants J Jermyn et al. 1989; Williams et al. 1989), so it is not surprising that $\operatorname{tag} B^{-}$mutants do not differentiate into stalk cells even when developed in mixed aggregates. However, it is not obvious why $\operatorname{tag} B^{-}$mutants developing in pure populations fail to sporulate because prespore cells appear to differentiate normally and they are fully capable of forming spores when developed in the presence of wild-type cells. It appears that spore maturation is gated by specialization of prestalk cells and resulting morphogenesis.

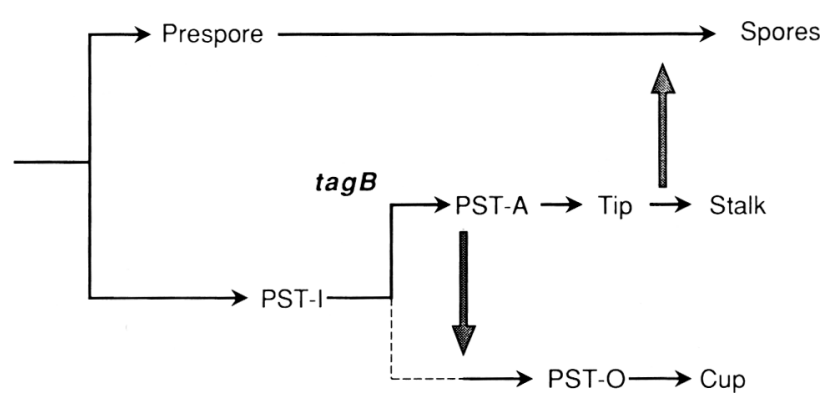

Figure 7. The involvement of $\operatorname{tag} B$ in prestalk specialization and in cell-cell communication. (Plain arrows) Cell lineage; (stippled arrows) intercellular communication (see text for details). 
Because TagB is essential for triggering encapsulation, peptides generated by its serine protease domain or those of the closely related proteases encoded by the linked genes, $\operatorname{tag} C$ and $\operatorname{tag} D$, may be used to signal prespore cells to encapsulate. Such peptide signals could be released from prestalk cells by the MDR transporter domains. A signal emanating from prestalk cells at the tip of culminants and diffusing to underlying prespore cells has been previously recognized from the pattern of expression of a late prespore gene, spiA (Richardson et al. 1994). This gene is initially expressed at the boundary of prestalk and prespore cells and subsequently in more distal cells over a period of several hours just prior to encapsulation. Our data identify the source of the signal as PST-A cells and suggest that the signal is a peptide that is processed and secreted by the TagB protein. Proteolytic processing and secretion of peptides could be a mechanism that integrates morphogenesis and differentiation via communication between cells and tissues during development in Dictyostelium and in other organisms.

\section{Materials and methods}

\section{Cells, growth, transformation and development}

Dictyostelium discoideum V12M2 cells were grown on SM agar plates (Sussman 1987) in association with Klebsiella aerogenes. AX4 and its pyr5-6 derivative HL 328 were grown in HL5 medium (Sussman 1987) supplemented with $20 \mu \mathrm{g} / \mathrm{ml}$ of uracil. G418-resistant strains TL43 (pyr5-6 act15::lacZ), TL51 (pyr56 ecmA::lacZ), TL82 (ecmA::Rm), TL86 (AX2 pstO::lacZ, a kind gift from Dr. J. Williams, University College, London, UK), TL88 (AX2 pyr5-6 pstO::lacZ), and the respective $\operatorname{tag} B$ pyr5$6^{+}$derivatives were grown in HL5 medium supplemented with $5 \mu \mathrm{g} / \mathrm{ml}$ of geneticin. Restriction enzyme-mediated integration, disruption of $\operatorname{tag} B$ by homologous recombination, and selection for uracil auxotrophs in FM medium were carried out as described by Kuspa and Loomis (1992). Transformation and G418 selection, development on filters, migration on agar plates, mixed development, detergent treatment of spores and sporulation assays were carried out as described by Shaulsky and Loomis (1993).

\section{Staining, enzyme activity, and bioassays}

$\mathrm{X}$-Gal staining was performed as before (Insall et al. 1994). $\beta$-Galactosidase was assayed as described by Fosnaugh and Loomis (1993). In mixing experiments, $50 \%$ lacZ transformants were mixed with $50 \%$ of isogenic cells that did not carry the $l a c Z$ gene as a control for the dilution effect. Comparison of $\operatorname{tag} B$ " to wild-type cells was always to the parental $\operatorname{tag} B^{+}$cell line. Response of $\operatorname{tag} B^{-}$mutants to DIF-1, cAMP, and $\mathrm{Ca}^{2+}$ ions was determined as described by Fosnaugh and Loomis (1993), with the exception that cells were dissociated after $12 \mathrm{hr}$ of filter development and that DIF-l was added at $50 \mathrm{~nm} / \mathrm{hr}$, cAMP was added at $20 \mu \mathrm{M} / \mathrm{hr}$ and samples were collected every $2 \mathrm{hr}$. Note that $\mathrm{Ca}^{2+}$ ions were added to selected samples rather than to the buffer of all samples as in Berks and Kay (1990). Hexane extraction of DIF-1 from AX4 cells and from $\operatorname{tag} B^{-}$mutants, as well as the DIF-1 bioassay on V12M2 cells was performed according to Brookman et al. (1987 and references therein).

\section{Molecular cloning of tagB}

Cloning of flanking DNA from the REMI strain AK228 cut with EcoRI was performed as described (Kuspa and Loomis 1992), and the entire insert was sequenced. The plasmid (p228Ec) was digested with $B a m H I$ and $B g / I I$ and a 1.2-kb fragment was gel purified and used as a probe to clone DNA from the rest of the gene. For inverse PCR, AX4 genomic DNA was digested with $B g l I$ and size selected to $1.4-2.8 \mathrm{~kb}$ by agarose gel electrophoresis and electroelution. DNA was diluted, ligated to promote circularization, and amplified with oligonucleotides from the sequenced portion of the gene. The PCR product $(1 \mathrm{~kb})$ was cloned into pGEM3 (Promega) and sequenced. A cDNA library was prepared (Stratagene) from poly(A)-selected RNA extracted from AX4 cells that have developed on filters for $10 \mathrm{hr}$ mixed with poly $(A)$-selected RNA extracted from AX4 slugs that had migrated for $45 \mathrm{hr}$. The library was screened with probes from the genomic DNA clones, and positive clones were sequenced. AX4 DNA was digested with ClaI, size-selected by gel electrophoresis to $5-7 \mathrm{~kb}$, digested with $B a m H I$, and size-selected again to 2.5-3.5 kb. DNA was ligated with AccI-BamHI-digested pGEM3 and transformed into SURE cells (Stratagene). Colonies were screened with probes from the $5^{\prime}$ end cDNA clones and positive clones were sequenced. A similar approach was used to clone an EcoRI-ClaI fragment between $\operatorname{tag} B$ and $\operatorname{tag} C$ and genomic DNA and cDNA from tagC (see map in Fig. 2). Both DNA strands from all of the clones were sequenced by use of the Sequenase system (U.S. Biochemical). The expression vector for $\operatorname{tag} B$ was made by combining overlapping genomic clones from the EcoRI site in $\operatorname{tag} C$ to the BglII site at the $3^{\prime}$ end of the inverse PCR product form $\operatorname{tag} B$ into an XhoI-XbaI digested pDdGall 7 (Harwood and Drury 1990), deleting the lac $Z$ sequences but retaining the Neo-resistance cassette, such that the $\operatorname{tag} B$ sequence was followed by a transcriptional termination signal from actin 8 .

\section{Nucleic acid analysis}

Genomic DNA was prepared and analyzed on Southern blots and RNA was prepared and analyzed on Northern blots as described (Shaulsky and Loomis 1993). Separation of cell types on Percoll (Pharmacia) gradients was performed according to Ratner and Borth (1983). RNA was extracted from the respective fractions and analyzed as above. Selection of polyadenylated RNA from total RNA was performed on $100 \mu \mathrm{g}$ of total RNA aliquots with oligo(dT)-cellulose (batch affinity chromatography) according to Sambrook et al. (1989). Probes for ecmA and $\cot B$ were as described (Shaulsky and Loomis 1993|. Probe A for $\operatorname{tag} B$ (Fig. 2a) was prepared by cloning an EcoRI-BglII DNA fragment $3^{\prime}$ of the BglI site in tagB into pGEM3 (Promega), digestion with Sau3AI and transcription in vitro with T7 RNA polymerase (BRL) in the presence of $\left[{ }^{32} \mathrm{P} \mid \mathrm{CTP}\right.$ to generate a radioactive 150-bp long transcript. Probe B (Fig. 2a) was prepared from an EcoRI-BamHI DNA fragment $5^{\prime}$ of IS228.

\section{Protein analysis}

The synthetic peptide KARSNGENSTDQAGDGSLP represents amino acid $666-683$ of $\mathrm{TagB}$, with an added lysine $(\mathrm{K})$ at the amino terminus and a substitution of cysteine (C) with an alanine $|A|$ at amino acid 13 of the peptide. The peptide was synthesized at the peptide synthesis facility, Center of Molecular Genetics at University of California, San Diego, an aliquot was conjugated to PPD (Statens Seruminstitute, Copenhagen, Denmark) according to Lachmann et al. (1986) and antibodies were 
raised in rabbits by Scantibodies Lab. Inc. (Ramona, CA). IgG was purified from crude antisera by affinity chromatography on protein A-cellulose (Sigma). Cells were collected at different stages of development, resuspended in $50 \mathrm{~mm}$ Tris- $\mathrm{HCl}(\mathrm{pH} 8.0)$, $5 \mathrm{~mm}$ EDTA, $150 \mathrm{~mm} \mathrm{NaCl}, 0.5 \%$ Nonidet-40, $1 \mathrm{~mm}$ PMSF, and protein concentration was determined using Bio-Rad protein assay reagent. Equal amounts of protein were resolved on $6 \%$ polyacrylamide-SDS gels (Laemmli 1970), electrotransfered to nitrocellulose membranes and detected with $2 \mu \mathrm{g} / \mathrm{ml}$ of the purified IgG antibody against TagB followed by incubation with alkaline-phosphatase-conjugated goat anti-rabbit antibody and color development according to the ProtoBlot (Promega) protocol.

\section{Computer sequence tools}

Predicted amino acid sequence and hydropathy plot (Kyte and Doolittle 1982) were performed with DNA Strider 1.2 and with MacVector 3.5 (IBI). Protein data base searches were carried out with BLAST (Altschul et al. 1990).

\section{Acknowledgments}

We thank Dr. J.G. Williams for pstO::lacZ and ecmA::Rm strains and plasmids, Dr. R.R. Kay for DIF metabolism assays, and M. Floyd for excellent technical assistance. This work was supported by the National Institutes of Health. G.S. was supported by a California Division-American Cancer Society, fellowship S-4-94.

The publication costs of this article were defrayed in part by payment of page charges. This article must therefore be hereby marked "advertisement" in accordance with 18 USC section 1734 solely to indicate this fact.

\section{References}

Altschul, S.F., W. Gish, W. Miller, E.W. Myers, and D.J. Lipman. 1990. Basic local alignment search tool. I. Mol. Biol. 215: 403-410.

Ames, G.F.-L. 1986. The basis of multidrug resistance in mammalian cells: Homology with bacterial transport. Cell 47: 323-324.

Berks, M. and R.R. Kay. 1990. Combinatorial control of cell differentiation by cAMP and DIF-1 during development of Dictyostelium discoideum. Development 110: 977-984.

Brookman, J.J., K.A. Jermyn, and R.R. Kay. 1987. Nature and distribution of the morphogen DIF in the Dictyostelium slug. Development 100: 119-124.

Chen, C.j., J.E. Chin, K. Ueda, D.P. Clark, I. Pastan, M.M. Gottesman, and I.B. Roninson. 1986. Internal duplication and homology with bacterial transport proteins in the mdrl(P-glycoprotein) gene from multidrug-resistant human cells. Cell 47: 381-389.

Deverson, E.V., I.R. Gow, W.J. Coadwell, J.J. Monaco, G.W Butcher, and J.C. Howard. 1990. MHC class II region encoding proteins related to the multidrug resistance family of transmembrane transporters. Nature 348: 738-741.

Early, A.E., M.J. Gaskell, D. Traynor, and J.G. Williams. 1993. Two distinct populations of prestalk cells within the tip of the migratory Dictyostelium slug with differing fates at culmination. Development 118: 353-362.

Fosnaugh, K.L. and W.F. Loomis. 1991. Coordinate regulation of the spore coat genes in Dictyostelium discoideum. Dev. Genet. 12: 123-132.

-1 1993. Enhancer regions responsible for temporal and cell-type-specific expression of a spore coat gene in Dictyos- telium. Dev. Biol. 157: 38-48.

Harwood, A.J. and L. Drury. 1990. New vectors for expression of the E. coli lacZ gene in Dictyostelium. Nucleic Acids Res. 18: 4292.

Harwood, A.J., A.E. Early, K.A. Jermyn, and J. Williams. 1991. Unexpected localization of cells expressing a prespore marker of Dictyostelium discoideum. Differentiation 46: 713.

Harwood, A.J., N.A. Hopper, M.N. Simon, D.M. Driscoll, M. Veron, and J.G. Williams. 1992. Culmination in Dictyostelium is regulated by the cAMP-dependent protein kinase. Cell 69: 615-624.

Insall, R., A. Kuspa, P.J. Lilly, G. Shaulsky, L.R. Levin, W.F. Loomis, and P. Devreotes. 1994. CRAC, a cytosolic protein containing a pleckstrin homology domain, is required for receptor and G protein-mediated activation of adenylyl cyclase in Dictyostelium. J. Cell Biol. 126: 1537-1545.

Jermyn, K.A., K.T. Duffy, and J.G. Williams. 1989. A new anatomy of the prestalk zone in Dictyostelium. Nature 340: 144 146.

Kraut, J. 1977. Serine proteases: Structure and mechanism of catalysis. Annu. Rev. Biochem. 46: 331-358.

Kuchler, K., R.E. Sterne, and J. Thorner. 1989. Saccharomyses cerevisiae STE6 gene product: A novel pathway for protein export in eukaryotic cells. EMBO J. 8: 3973-3984.

Kuspa, A. and W.F. Loomis. 1992. Tagging developmental genes in Dictyostelium by restriction enzyme-mediated integration of plasmid DNA. Proc. Natl. Acad. Sci. 89: 8803-8807. . 1994. REMI-RFLP mapping of the Dictyostelium genome. Genetics 138: 665-674.

Kyte, J. and R.F. Doolittle. 1982. A simple method for displaying the hydropathic character of a protein. J. Mol. Biol. 157: 105132.

Lachmann, P.J., L. Strangeways, A. Vyakarnam, and G. Evan. 1986. Raising antibodies by coupling peptides to PPD and immunizing BCG-sensitized animals. Synthetic peptides as antigens. CIBA Found. Symp. 25-57.

Laemmli, U.K. 1970. Cleavage of structural proteins during the assembly of the head of bacteriophage T4. Nature 227: 680 685 .

Loomis, W.F. 1993. Lateral inhibition and pattern formation in Dictyostelium. Curr. Top. Dev. Biol. 28: 1-45.

Loomis, W.F., A. Kuspa, and G. Shaulsky. 1994. Gene discovery in Dictyostelium. Genet. Eng. 16: 49-64.

McGarth, J.P. and A. Varshavsky. 1989. The yeast STE6 gene encodes a homologue of the mammalian multidrug resistance P-glycoprotein. Nature 340: 400-404.

Michaelis, S. 1993. STE6, the yeast a-factor transporter. Sem. Cell Biol. 4: 17-27.

Monaco, J.J., S. Cho, and M. Attaya. 1990. Transport protein genes in the murine MHC: Possible implication for antigen processing. Science 250: 1723-1726.

Pastan, I. and M.M. Gottesman. 1991. Multidrug resistance. Annu. Rev. Med. 42: 277-286.

Raper, K.B. 1940. Pseudoplasmodium formation and organization in Dictyostelium discoideum. I. Elisha Mitchell Sci. Soc. 59: 241-282.

Ratner, D. and W. Borth. 1983. Comparison of differentiating Dictyostelium discoideum cell types separated by an improved method of density gradient centrifugation. Exp. Cell Res. 143: 1-13.

Richardson, D., C.B. Hong, and W.F. Loomis. 1991. A prespore gene, Dd31, expressed during culmination of Dictyostelium discoideum. Dev. Biol. 144: 269-280.

Richardson, D.L., W.F. Loomis, and A.R. Kimmel. 1994. Progression of an inductive signal activates sporulation in Dic- 


\section{Shaulsky et al.}

tyostelium discoideum. Development 120: 2891-2900.

Sambrook, J., E.F. Fritsch, and T. Maniatis. 1989. Molecular cloning: A laboratory manual. Cold Spring Harbor Laboratory Press, Cold Spring Harbor, New York.

Shaulsky, G. and W.F. Loomis. 1993. Cell type regulation in response to expression of ricin A in Dictyostelium. Dev. Biol. 160: 85-98.

Spies, T., M. Bresnahan, S. Bahram, D. Arnold, G. Blanck, E. Mellins, D. Pious, and R. DeMars. 1990. A gene in the human major histocompatibility complex class II region controlling the class I antigen presentation pathway. Nature 348: 744-747.

Spies, T., V. Cerundolo, M. Colonna, P. Cresswell, A. Townsend, and R. Demars. 1992. Presentation of viral antigen by MHC class I molecules is dependent on a putative peptide transporter heterodimer. Nature 355: 644-646.

Sternfeld, J. and C. David. 1982. Fate and regulation of anteriorlike cells in Dictyostelium slugs. Dev. Biol. 93: 111-121.

Sussman, M. 1987. Cultivation and synchronous morphogenesis of Dictyostelium under controlled experimental conditions. Methods Cell Biol. 28: 9-29.

Townsend, A.R.M., F.M. Gotch, and J. Davey. 1985. Cytotoxic $T$ cell recognize fragments of the influenza nucleoprotein. Cell 42: 457-467.

Trowsdale, J., I. Hanson, I. Mockridge, S. Beck, A. Townsend, and A. Kelly. 1990. Sequence encoded in the class II region of the MHC related to the ABC superfamily of transporters. Nature 348: 741-744.

Vos, P., G. Simons, R.J. Siezen, and W.M. de Vos. 1989. Primary structure and organization of the gene for a procaryotic, cell envelope-located serine proteinase. I. Biol. Chem. 264: 13579-13585.

Williams, J.G., K.T. Duffy, D.P. Lane, S.J. McRobbic, A.J. Harwood, D. Traynor, R.R. Kay, and K.A. Jermyn. 1989. Origins of the prestalk-prespore pattern in Dictyostelium development. Cell 59: 1157-1163. 


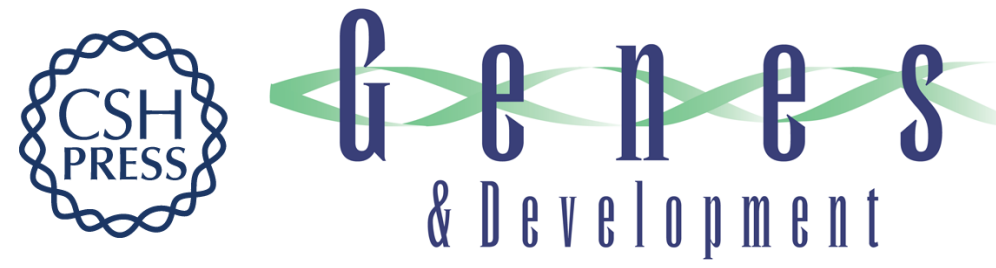

\section{A multidrug resistance transporter/serine protease gene is required for prestalk specialization in Dictyostelium.}

G Shaulsky, A Kuspa and W F Loomis

Genes Dev. 1995, 9:

Access the most recent version at doi:10.1101/gad.9.9.1111

References This article cites 39 articles, 9 of which can be accessed free at:

http://genesdev.cshlp.org/content/9/9/1111.full.html\#ref-list-1

License

Email Alerting

Service

Receive free email alerts when new articles cite this article - sign up in the box at the top right corner of the article or click here.

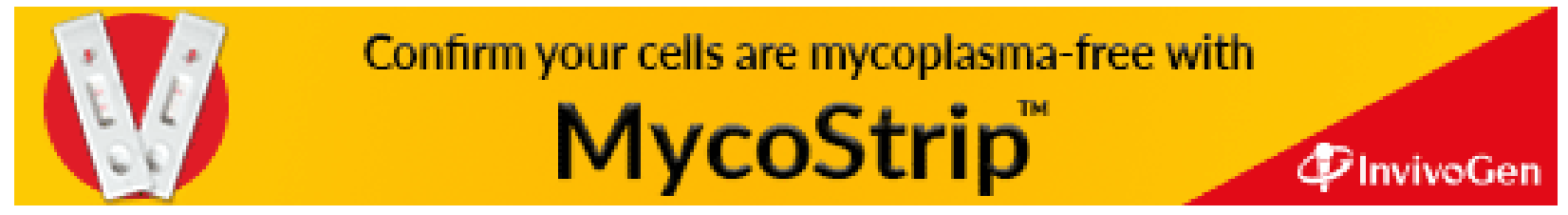

